\title{
VARIABILIDADE ESPACIAL E ANÁLISE MULTIVARIADA DOS ATRIBUTOS FÍSICOS DO SOLO EM UMA MICROBACIA DO RIO PANDEIROS
}

\author{
SPATIAL VARIABILITY AND MULTIVARIATE ANALYSIS OF SOIL PHYSICAL PROPERTIES IN A PANDEIROS RIVER MICRO \\ BASIN
}

VARIABILIDAD ESPACIAL Y ANÁLISIS MULTIVARIADO DE PROPIEDADES FÍSICAS DEL SUELO EN UNA MICROCUENCA DEL RÍO PANDEIROS

\section{RESUMO}

Introdução: O levantamento dos atributos físicos do solo e do relevo é primordial para o monitoramento das modificações ambientais decorrentes das ações antrópicas. Objetivos: Objetivou-se caracterizar os atributos físicos do solo em uma microbacia do rio Pandeiros, Várzea Bonita, distrito de Januária-MG, determinando a variabilidade espacial das estimativas desses atributos e analisar de forma multivariada quais atributos refletem a variância na área considerada. Métodos: Foram amostrados vinte e cinco pontos georreferenciados de solo, sendo caracterizados os atributos físicos e o relevo. Resultados: O mapeamento do solo na microbacia em estudo indicou dependência espacial para a maioria dos atributos físicos do solo, com exceção da condutividade hidráulica do solo saturado. A análise multivariada dos atributos físicos do solo baseada nos componentes principais explicou $95,72 \%$ da variabilidade dos dados na microbacia, possibilitando delimitar os atributos mais sensíveis no monitoramento das modificações ocorridas no solo. Conclusão: Os teores de areia média, areia fina e areia muito fina são os atributos que mais refletem as modificações ocorridas no solo.

Palavras-chave: Erosão. Estatística descritiva. Geoestatística. Krigagem. Componentes principais

\section{ABSTRACT}

Introduction: The survey of the soil physical attributes and the relief is paramount for the monitoring of the environmental modifications resulting from the anthropic actions. Objetive: The objective of this study was to characterize the soil physical attributes in a Pandeiros river micro basin, Várzea Bonita district, Januária, Minas Gerais, Brazil, determining the spatial variability of the attributes and to analyze in a multivariate manner which attributes reflect the variance in the area considered. Methods: Twenty-five soil georeferenced points were sampled, some physical attributes were characterized and the relief. Results: Soil mapping in the studied micro basin indicated spatial dependence for most of the soil physical attributes, except for the saturated soil hydraulic conductivity. The multivariate analysis of soil physical attributes based on the main components explained $95.72 \%$ of data variability in the micro basin, making it possible to delimit more sensitive attributes in the monitoring of changes occurring in the soil. Conclusions: The medium sand, fine sand, and very fine sand levels are the attributes that most reflect soil changes.

Keywords: Erosion. Descriptive statistics. Geostatistics. Kriging. Principal components.

\section{RESUMEN}

Introducción: El levantamiento de los atributos físicos del suelo y el relieve es primordial para el seguimiento de las modificaciones ambientales resultantes de las acciones antrópicas. Objetivo: El objetivo de este estudio fue caracterizar los atributos físicos del suelo en una microcuenca del río Pandeiros, distrito de Várzea Bonita, Januária, Minas Gerais, Brasil, determinando la variabilidad espacial de los atributos y analizar de manera multivariada qué atributos reflejan el variación en el área considerada. Métodos: Se muestrearon veinticinco puntos georreferenciados del suelo, se caracterizaron algunos atributos físicos y el relieve. Resultados: El mapeo de suelos en la microcuenca estudiada indicó dependencia

\author{
Pablo Fernando Santos Alves ${ }^{\text {a }}$ \\ Marcos Koiti Kondo a \\ Derônica Godinho Ferreira ${ }^{a}$ \\ Denato Fernandes Silva ${ }^{a}$ \\ João Victor Santos Guerra a \\ ${ }^{a}$ Universidade Estadual de Montes \\ Claros (UNIMONTES), Montes Claro, MG \\ Brasil
}

DOI: 10.12957/geouerj.2021.40190

Correpondência:

agrotecnico10@yahoo.com.br

Recebido em: 15 fev. 2019

Aceito em: 14 mar.2021 
espacial para la mayoría de los atributos físicos del suelo, excepto para la conductividad hidráulica del suelo saturado. El análisis multivariado de los atributos físicos del suelo basado en los componentes principales explicó el 95,72\% de la variabilidad de los datos en la microcuenca, permitiendo delimitar atributos más sensibles en el seguimiento de los cambios que ocurren en el suelo. Conclusiones: Los niveles de arena media, arena fina y arena muy fina son los atributos que más reflejan los cambios del suelo.

Palabras-clave: Erosión. Estadísticas descriptivas. Geoestadística. Kriging. Componentes principales. 


\section{INTRODUÇÃO}

O mapeamento dos atributos físicos do solo tem se tornado a cada dia primordial na quantificação e no monitoramento dos recursos naturais, uma vez que permitirá entre outros aspectos, identificar áreas mais propensas aos processos erosivos e assim, a necessidade de adoção de práticas conservacionistas pontuais para conservação, especialmente o solo e a água.

De acordo com Moraes et al. (1993), é comum encontrar em campo diferenças no valor de um parâmetro de uma, duas ou três ordens de grandeza entre pontos separados por poucos metros. Diante de tais variações, seria incorreto considerar apenas os valores médios para fins que dependem intimamente desses atributos, tais como em projetos de manejo e conservação ambiental, sobretudo quando os valores amostrais não apresentam distribuição normal (EGUGHI et al., 2002).

Dessa forma, a geoestatística auxilia na identificação e mapeamento dos atributos do solo, em virtude da possibilidade de interpretação dos resultados com base na estrutura da variabilidade dos atributos avaliados, considerando a dependência espacial dentro do intervalo de amostragem. Inclui nesse contexto os estudos relacionados às perdas de solo por erosão e os fatores que por ventura tenham relação com a sua ocorrência, facilitando a tomadas de decisões que tenham a finalidade de mitigação do problema (MARCHETTI et al., 2012; PICCINI et al., 2014; MIQUELONI et al., 2015; BHUNIA et al., 2018; CERRETELLI et al., 2018; YE et al., 2018).

Segundo Cambardella et al. (1994), a variabilidade dos atributos físicos do solo pode ser de origem intrínseca ou extrínseca. A variabilidade intrínseca possui forte dependência espacial, sendo causada por alterações naturais no solo, notadamente aquelas de origem pedogenética, como: material de origem, intemperismo de minerais, acúmulo de matéria orgânica e outros. A variabilidade extrínseca possui menor dependência espacial, sendo causada por alterações no uso do solo, como: práticas culturais, espécie vegetal explorada, erosão, compactação, entre outros.

Uma das grandes dificuldades quando se trabalha com um volume muito grande de parâmetros é a dificuldade em definir quais são aqueles mais expressivos para inferir possíveis mudanças no ambiente, sejam essas decorrentes de ações antrópicas ou mesmo naturais. Nesse panorama, a análise multivariada permite definir quais parâmetros são mais sensíveis a essas modificações. O que poderia resultar em economia por menor dispêndio de material humano, logístico e financeiro no levantamento de informações do solo, uma vez reduzida a necessidade de parâmetros a serem coletados. Alves et al. (2014) mencionam que as técnicas de análise multivariada em conjunto com a geoestatística facilitam a avaliação da variabilidade espacial dos atributos físico-químicos do solo, pois diminuem o número de mapas a serem analisados. Utilizando as duas técnicas, Bueno et al. (2011) verificaram a possibilidade de distinguir classes de solo em uma mesma área. 
Dessa maneira o objetivo do trabalho foi mapear a variabilidade espacial dos atributos físicos do solo e identificar por meio de análise multivariada aqueles que melhor expressam a variabilidade em uma microbacia com erosão acentuada.

\section{MATERIAL E MÉTODOS}

A área de estudo localiza-se nas coordenadas UTM (Datum WGS-84): Z23 479107E 8318800S, com clima Aw, a montante da Pequena Central Hidrelétrica (PCH) Pandeiros, próximo ao distrito de Várzea Bonita, Januária-MG. $\mathrm{O}$ levantamento de solos utilizou como base o mapa de solos de Minas Gerais, sendo validado com visitas a campo. A análise dos resultados considerou dados analíticos de amostragem dos solos e a descrição morfológica dos perfis. As classes de solos predominantes na microbacia em estudo são o Neossolo Quartzarênico Órtico típico (RQo), dominando as regiões elevadas da paisagem formada a partir dos arenitos do Grupo Urucuia e, o Neossolo Litólico Distrófico típico (RLd) nas maiores declividades, associando-se com RQo. Considerada num aspecto geral, predomina na paisagem o bioma cerrado, fragilizado pela remoção ou dano à cobertura vegetal nativa. Essa depreciação esta atribuída principalmente a exploração do cerrado para carvão nas décadas de 1970 e 80, associadas à pecuária extensiva sobre solos de fertilidade limitada com baixa reserva de nutrientes e pH, o que intensificou a erosão laminar e levou ao voçorocamento, ainda ativo (Figura 1), aumentando a pressão sobre as veredas.

Figura 1. Local da microbacia estudada e contorno da área amostrada para composição dos mapas de variabilidade das perdas de solo (linha amarela). Fonte: Google Earth.

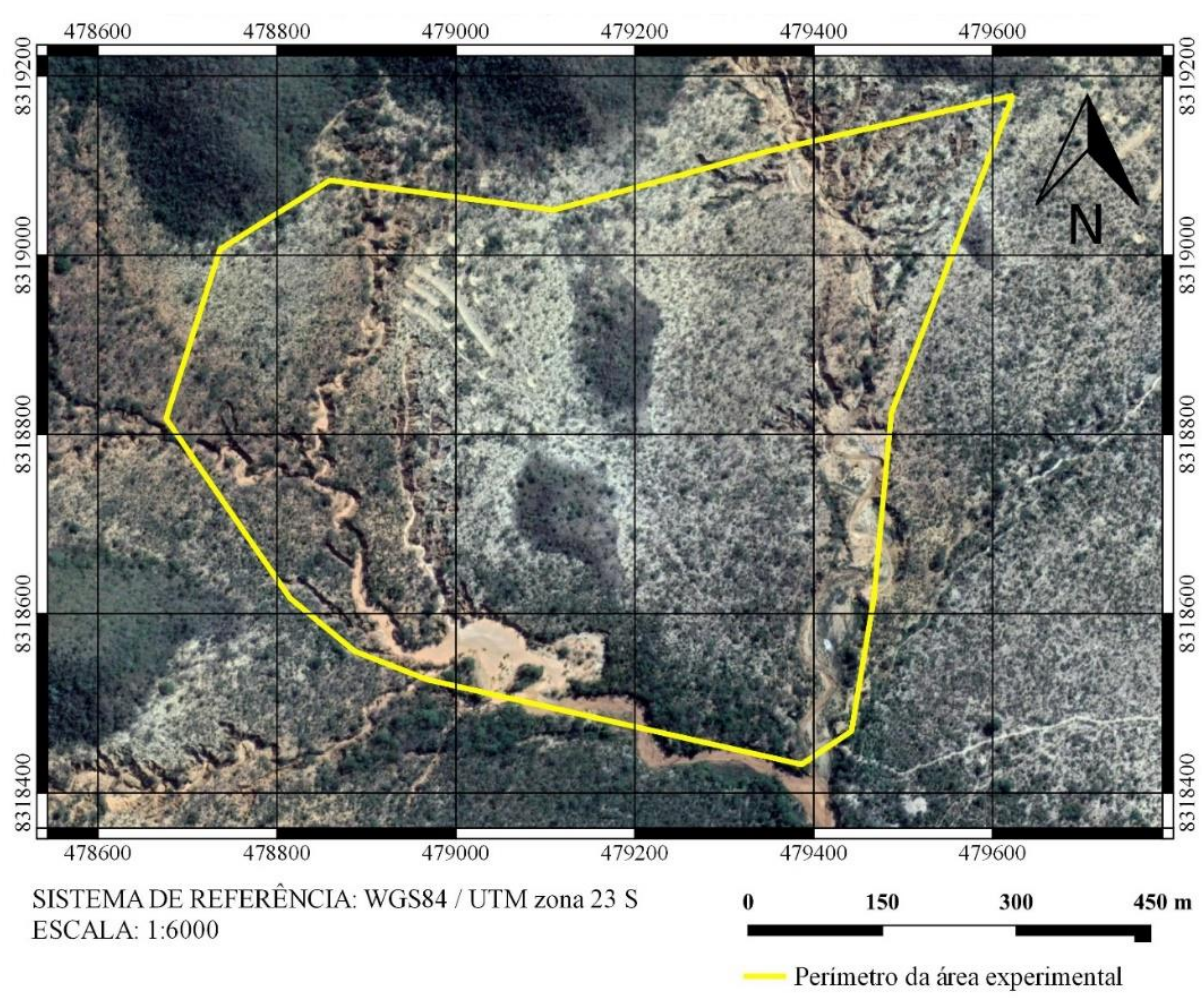


Os atributos físicos do solo e do relevo foram avaliados in loco ou a partir da coleta e análise de amostras deformadas (com auxílio de enxadão) e indeformadas (utilizando anéis volumétricos de aproximadamente $100 \mathrm{~cm}^{3}$ ) na profundidade de 0-0,2 m. Foram determinados os seguintes atributos físicos do solo e do relevo: análise granulométrica (textura) com fracionamento de areias nas seguintes classes: Areia Muito Grossa (AMG), 2-1 mm; Areia Grossa (AG), 1 0,5 mm; Areia Média (AM), 0,5-0,25 mm; Areia Fina (AF), 0,25-0,106 mm; Areia Muito Fina (AMF), 0,106-0,053 mm, realizada conforme EMBRAPA (2012); Densidade de partículas (DP): realizada pelo método do balão volumétrico (EMBRAPA, 2017); Resistência do solo a penetração (RP) - realizada com um penetrômetro de impacto Stolf (STOLF et al., 2014), sendo obtidas a média ponderada da resistência à penetração do solo no perfil avaliado (RPmed); Umidade do solo $(\theta)$ - foram realizadas utilizando técnica de reflectometria de domínio no tempo (TDR) a partir de um equipamento da marca IMKO, utilizando sondas Trime-Pico 64, acopladas a um coletor de dados modelo Globelog Logger V 1.0 previamente calibrado (FERREIRA et al., 2016b); Volume total de poros determinado (VTPd), a macroporosidade total (MAPT) e a microporosidade total (MIPT) determinados conforme EMBRAPA (2017); Densidade do Solo (DS) - determinada conforme Grossman e Reinsch (2002); Declividade (DEC) - realizada com o auxílio de um nível de mangueira, sendo tomada a média de três leituras no sentido de escoamento nas parcelas experimentais em cada ponto de coleta.; Condutividade hidráulica do solo saturado (Ksat) - Determinada pelo método do permeâmetro de carga constante (YOUNGS, 1991).

As coordenadas geográficas dos pontos de coletas dos dados foram obtidas com GPS Trimble Juno SC, configurado no Datum WGS-84, fuso $23 \mathrm{~S}$. A figura 01 apresenta os contornos e um aspecto geral da microbacia em estudo, cuja área delimitada pelos pontos de coleta foi de 45,4 ha. Os dados meteorológicos foram obtidos por meio de uma estação meteorológica instalada nas proximidades da área experimental (Longitude: 480494 E, Latitude: 8317355 S, na projeção UTM).

Os dados foram inicialmente submetidos a uma análise descritiva, considerando os seguintes parâmetros: média, coeficiente de variação (CV), coeficiente de assimetria (AS), curtose (Curt.), normalidade através dos testes KolmogorovSmirnov (KS) e teste Shapiro-Wilk (SW). Foi calculada também a correlação de Spearman entre os dados amostrais.

Foram calculadas as semivariâncias dos dados para as distâncias (h) entre os pontos, o ajuste e a seleção dos modelos dos semivariogramas foram realizados com base na menor soma de quadrados do resíduo (SQR), no maior coeficiente de determinação $\left(r^{2}\right)$ e no avaliador do grau de dependência espacial (GDE) utilizando o software GS Plus 7.0 versão Demo $\left(\mathrm{GS}^{+}\right.$, 2004). Posteriormente foi realizada a interpolação por meio da krigagem em blocos $2 \times 2$, para estimar os valores dos atributos nas áreas não amostradas, permitindo a confecção dos mapas bidimensionais de isolinhas. Os mapas de isolinhas foram delineados no programa Surfer 13.0 Versão Demo (GOLDEN SOFTWARE, 2016), Datum WGS-84 em UTM fuso 23.

Os dados foram comparados de forma multivariada por meio da análise de componentes principais utilizando o software R (R CORE TEAM, 2016). 


\section{RESULTADOS E DISCUSSÃO}

A análise descritiva dos dados, também chamada de inferencial ou exploratória é apresentada na tabela 1. De acordo com Gomes et al. (2007) a análise exploratória não espacial dos dados mostra-se como importante ferramenta no estudo de atributos físico-hídricos do solo, eliminando candidatos a outliers, sendo possível observar aqueles que apresentam baixa média ou alta variabilidade espacial, estabelecendo a sua estrutura de dependência.

Tabela 1. Estatística descritiva dos dados dos atributos físicos do solo e do relevo em uma microbacia do rio Pandeiros, Várzea Bonita, Januária-MG. Fonte: Os autores.

\begin{tabular}{lllllll}
\hline Atributo & Unidade & Média & CV & AS & Curt. & SW \\
\hline ALT & $\mathrm{m}$ & 670,59 & 1,45 & $-0,59$ & 0,23 & $0,96^{\mathrm{ns}}$ \\
DEC & $\%$ & 5,94 & 52,16 & 0,03 & $-0,63$ & $0,97^{\mathrm{ns}}$ \\
ARG & $\mathrm{g} \mathrm{kg}^{-1}$ & 68,64 & 30,13 & 0,62 & $-0,86$ & $0,91^{*}$ \\
SILTE & $\mathrm{g} \mathrm{kg}^{-1}$ & 18,12 & 43,99 & 0,78 & 0,40 & $0,94^{\mathrm{ns}}$ \\
AREIA & $\mathrm{g} \mathrm{kg}^{-1}$ & 913,28 & 2,51 & $-0,75$ & $-0,74$ & $0,89^{*}$ \\
AMG & $\mathrm{g} \mathrm{kg}^{-1}$ & 2,44 & 81,18 & 0,27 & $-0,61$ & $0,91^{*}$ \\
AG & $\mathrm{g} \mathrm{kg}^{-1}$ & 3,84 & 37,35 & 0,58 & 0,01 & $0,90^{*}$ \\
AM & $\mathrm{g} \mathrm{kg}^{-1}$ & 94,92 & 59,94 & 1,07 & 0,33 & $0,85^{* *}$ \\
AF & $\mathrm{g} \mathrm{kg}^{-1}$ & 269,32 & 29,71 & 0,26 & $-1,02$ & $0,95^{\mathrm{ns}}$ \\
AMF & $\mathrm{g} \mathrm{kg}^{-1}$ & 542,84 & 22,66 & $-0,60$ & $-0,57$ & $0,94^{\mathrm{ns}}$ \\
VTPd & $\mathrm{cm}^{3} \mathrm{~cm}^{-3}$ & 0,43 & 6,85 & 0,00 & $-0,25$ & $0,98^{\mathrm{ns}}$ \\
MAPT & $\mathrm{cm}^{3} \mathrm{~cm}^{-3}$ & 0,16 & 27,02 & 0,64 & 0,35 & $0,95^{\mathrm{ns}}$ \\
MIPT & $\mathrm{cm}^{3} \mathrm{~cm}^{-3}$ & 0,27 & 11,93 & $-0,32$ & 0,07 & $0,98^{\mathrm{ns}}$ \\
DS & $\mathrm{g} \mathrm{cm}^{-3}$ & 1,49 & 4,91 & $-0,17$ & 0,14 & $0,98^{\mathrm{ns}}$ \\
DP & $\mathrm{g} \mathrm{cm}^{-3}$ & 2,58 & 1,50 & 0,01 & $-0,02$ & $0,95^{\mathrm{ns}}$ \\
Ksat & $\mathrm{cm} \mathrm{s}^{-1}$ & 0,0028 & 57,66 & 1,21 & 1,50 & $0,90^{*}$ \\
RP & $\mathrm{MPa}^{\boldsymbol{\theta}}$ & 4,34 & 38,08 & 1,03 & 1,12 & $0,91^{*}$ \\
\hline
\end{tabular}

Atributos Avaliados: Altitude (ALT), declividade (DEC), argila (ARG), silte (SILTE), areia total (AREIA), areia muito grossa (AMG), areia grossa (AG), areia média (AM), areia fina (AF), areia muito fina (AMF), volume total de poros determinado (VTPd), macroporosidade total (MAPT), microporosidade total (MIPT), densidade do solo (DS), densidade de partículas (DP), condutividade hidráulica do solo saturado (Ksat), resistência do solo à penetração (RP) e umidade do solo ( $\Theta$ ). Parâmetros estatísticos: Média, coeficiente de variação (CV), coeficiente de assimetria (AS), curtose (Curt), teste Shapiro Wilk (SW). Significativo a $5 \%(*)$; significativo a $1 \%\left({ }^{* *}\right)$; não significativo $\left({ }^{\text {ns }}\right)$.

Os coeficientes de variação (CV) foram comparados considerando os limites propostos por Warrick e Nielsen (1980), sendo: $C V<12 \%, 12 \%<C V<60 \%$ e CV $>60 \%$, considerados de baixa, média e alta variabilidade, respectivamente. Sendo assim, classificou-se os dados como de baixa ou média variabilidade em sua grande maioria, a única exceção foi o teor de areia muito grossa (AMG), que indicou alto coeficiente de variação, possivelmente em virtude da presença de valores zeros na amostra obtida. 
Os valores de assimetria (AS) positiva demonstram tendência de concentração dos valores abaixo da média observada, sendo tal tendência tanto mais expressiva quanto maior for o valor obtido; situação inversa se dá para valores negativos desse coeficiente (CORADO NETO et al., 2015). Verifica-se (Tabela 1) que a distribuição do conjunto de dados para a maioria dos atributos do relevo e do solo, com exceção da altitude (ALT), teor de areia, areia muito fina (AMF), microporosidade total (MIPT), densidade do solo (DS), apresentaram assimetria positiva, indicando que a presença de valores extremos contribuiu para distorcer a média dos dados, aumentando-a artificialmente.

Os dados de declividade (DEC), argila (ARG), areia, areia muito grossa (AMG), areia fina (AF), areia muito fina (AMF), volume total de poros (VTPd) e densidade de partículas (DP) apresentaram distribuição de frequência platicúrtica, ou seja, com curtose menor que zero, mostrando uma tendência desses atributos apresentarem maior dispersão dos dados em torno das suas médias (Tabela 1). Os demais atributos apresentaram curtose positiva, ou seja, uma distribuição leptocúrtica, consequentemente, valores mais próximos em relação ao seu centro no gráfico de distribuição de frequências.

O teste de Shapiro Wilk (SW) para os dados amostrais indicou ausência de normalidade para os seguintes atributos: argila (ARG), areia, areia muito grossa (AMG), areia grossa (AG), areia média (AM), condutividade hidráulica do solo saturado (Ksat), resistência do solo à penetração (RP) e umidade do solo $(\theta)$. Ressalta-se que na análise geoestatística não há a premissa de normalidade do conjunto de dados para sua aplicação, no entanto, a normalidade dos dados possibilita melhor ajuste do semivariograma e consequentemente às inferências posteriores (CORÁ E BERALDO, 2006; MACHADO et al., 2007). De acordo com Yamamoto e Landim (2013), se os dados amostrais apresentam assimetria acentuada é necessário utilizar um estimador robusto para a determinação das semivariâncias ou realizar transformação de dados, como por exemplo, a transformação logarítmica.

A variabilidade espacial apresentou, no geral, estrutura de dependência para a maioria dos atributos do solo estudado. Sendo ajustados os semivariogramas descritos na Tabela 2. De acordo Vieira (2000) quanto mais simples for o modelo ajustado, melhor, e não se deve dar importância excessiva a pequenas flutuações que podem ser artifícios referentes a um pequeno número de dados. Segundo esse autor, o importante é que o modelo ajustado represente a tendência da variabilidade em relação à distância. Gomes et al. (2007) avaliando métodos de ajuste e modelos de semivariograma sugere o modelo esférico como mais apropriado ao estudo da variabilidade espacial de atributos físicohídricos do solo, o que foi verificado também por outros autores (GREGO; VIEIRA, 2005; FARACO et al., 2008). Nos fenômenos em que se ajusta o modelo esférico, o alcance real é finito, ao contrário do que é verificado para os modelos exponencial e gaussiano (SEIDEL; OLIVEIRA, 2013). Portanto, para os dados do presente trabalho foi utilizado o modelo esférico, considerando-se sempre que possível o ajuste do semivariograma de anisotropia. A anisotropia é a tendência que a variabilidade espacial possui de ser maior em uma direção que em outra perpendicular aquela, com diferentes alcances da dependência espacial (TRANGMAR, 1986; GUEDES et al., 2008). Para fins geoestatísticos o alcance (a) é 
entendido como distância dentro da qual as amostras apresentam-se correlacionadas espacialmente (TRANGMAR, 1986; VIEIRA, 2000).

Tabela 2. Parâmetros de ajuste dos semivariogramas (modelo esférico) dos atributos físicos do solo em diferentes períodos de avaliação em uma microbacia do rio Pandeiros, Januária-MG. Fonte: Os autores.

\begin{tabular}{llllllll}
\hline Atributo & $\begin{array}{l}\text { Efeito Pepita } \\
\text { Co }\end{array}$ & $\begin{array}{l}\text { Patamar } \\
(\mathbf{C + C o})\end{array}$ & a1 & a2 & SQR & $\mathbf{r}^{\mathbf{2}}$ & $\begin{array}{l}\text { GDE (\%) } \\
\text { (Co/[C+Co]) }\end{array}$ \\
\hline ALT & $2,38 \mathrm{E}+01$ & $2,93 \mathrm{E}+02$ & 1040 & 1430 & $1,40 \mathrm{E}+04$ & 0,79 & 8,12 \\
DEC & $5,30 \mathrm{E}-01$ & $1,08 \mathrm{E}+01$ & 235 & 291 & $2,10 \mathrm{E}+02$ & 0,65 & 4,91 \\
ARG & $1,00 \mathrm{E}-01$ & $3,75 \mathrm{E}+02$ & 130 & 140 & $4,55 \mathrm{E}+05$ & 0,25 & 0,03 \\
SILTE & $3,97 \mathrm{E}+01$ & $1,25 \mathrm{E}+02$ & 2520 & 5620 & $7,97 \mathrm{E}+03$ & 0,28 & 31,76 \\
AREIA & $3,63 \mathrm{E}+02$ & $1,37 \mathrm{E}+03$ & 2640 & 2640 & $6,77 \mathrm{E}+05$ & 0,18 & 26,50 \\
AMG & $1,13 \mathrm{E}-01$ & $2,91 \mathrm{E}+00$ & 200 & 200 & $1,11 \mathrm{E}+02$ & 0,21 & 3,88 \\
AG & $1,00 \mathrm{E}-03$ & $3,70 \mathrm{E}+00$ & 234 & 234 & $4,79 \mathrm{E}+01$ & 0,41 & 0,03 \\
AM & $1,51 \mathrm{E}+03$ & $6,39 \mathrm{E}+03$ & 1540 & 1540 & $6,93 \mathrm{E}+07$ & 0,35 & 23,63 \\
AF & $1,41 \mathrm{E}+03$ & $1,33 \mathrm{E}+04$ & 895 & 895 & $1,94 \mathrm{E}+08$ & 0,38 & 10,60 \\
AMF & $4,08 \mathrm{E}+03$ & $5,89 \mathrm{E}+04$ & 2030 & 2030 & $2,71 \mathrm{E}+09$ & 0,26 & 6,93 \\
VTPd & $5,40 \mathrm{E}-04$ & $2,42 \mathrm{E}-03$ & 2350 & 4920 & $2,79 \mathrm{E}-06$ & 0,28 & 22,31 \\
MAPT & $4,60 \mathrm{E}-04$ & $1,75 \mathrm{E}-03$ & 1140 & 5250 & $9,02 \mathrm{E}-06$ & 0,20 & 24,88 \\
MIPT & $1,01 \mathrm{E}-03$ & $4,06 \mathrm{E}-03$ & 2540 & 2540 & $1,35 \mathrm{E}-05$ & 0,25 & 14,32 \\
DS & $5,47 \mathrm{E}-04$ & $3,82 \mathrm{E}-03$ & 299 & 299 & $6,18 \mathrm{E}-05$ & 0,17 & 10,63 \\
DP & $5,04 \mathrm{E}-04$ & $4,74 \mathrm{E}-03$ & 811 & 1010 & $1,01 \mathrm{E}-05$ & 0,32 & 22,62 \\
Ksat & $7,42 \mathrm{E}-04$ & $3,28 \mathrm{E}-03$ & 94 & $*$ & $5,60 \mathrm{E}-12$ & 0,00 & 0,04 \\
RP & $1,00 \mathrm{E}-09$ & $2,57 \mathrm{E}-06$ & 555 & 555 & $3,34 \mathrm{E}+01$ & 0,48 & 7,28 \\
$\boldsymbol{\theta}$ & $2,38 \mathrm{E}-01$ & $3,27 \mathrm{E}+00$ & 323 & $*$ & $4,59 \mathrm{E}-02$ & 0,85 & 25,52 \\
\hline
\end{tabular}

Atributos avaliados: Altitude (ALT), declividade (\%), argila (ARG), silte (SILTE), areia total (AREIA), areia muito grossa (AMG), areia grossa (AG), areia média (AM), areia fina (AF), areia muito fina (AMF), volume total de poros determinado (VTPd), macroporosidade total (MAPT), microporosidade total (MIPT), densidade do solo (DS), densidade de partículas (DP), condutividade hidráulica do solo saturado (Ksat), resistência do solo à penetração (RP) e umidade do solo $(\Theta)$. Parâmetros do Semivariograma; Efeito pepita (Co); Patamar ( $C+C o)$; alcance menor (a1); alcance maior (a2); soma de quadrados do resíduo (SQR); coeficiente de determinação $\left(r^{2}\right)$; grau de dependência espacial (GDE). $\left(^{*}\right)$ Modelos ajustados considerando isotropia, o alcance é o mesmo em todas direções

A partir dos semivariogramas ajustados foi possível a construção dos mapas de variabilidade espacial para os atributos do relevo e do solo evidenciados nas figuras 2, 3 e 4. De acordo com Sampaio et al. (2010), o alcance da dependência espacial é um parâmetro geoestatístico importante na agricultura por auxiliar o delineamento de futuras amostragens de solo, indicando a máxima distância entre amostras para determinar atributos do solo com boa representatividade. Cambardella et al. (1994) classifica a dependência espacial da seguinte maneira: dependência espacial forte, efeito pepita $\leq 25 \%$; dependência espacial moderada, efeito pepita entre $25 \%$ e $75 \%$; e, dependência espacial fraca, quando o efeito pepita é > 75\%. Isso implica que, no geral, os dados apresentados, podem colaborar em 
futuras amostragens com finalidade de monitorar as transformações ambientais na região, principalmente aqueles compreendidos dentro dos processos erosivos. Para algumas variáveis verificou-se o alcance de dependência espacial maior que a máxima distância de amostragem dentro do grid georreferenciados (1013,12 m), o que segundo Pazini et al. (2015) indica que todos os pontos amostrados são altamente correlacionados.

Figura 2. Mapa dos atributos físicos do relevo: A) Altitude e B) Declividade em uma microbacia do rio Pandeiros, Várzea Bonita, Januária-MG. Fonte: Os autores.
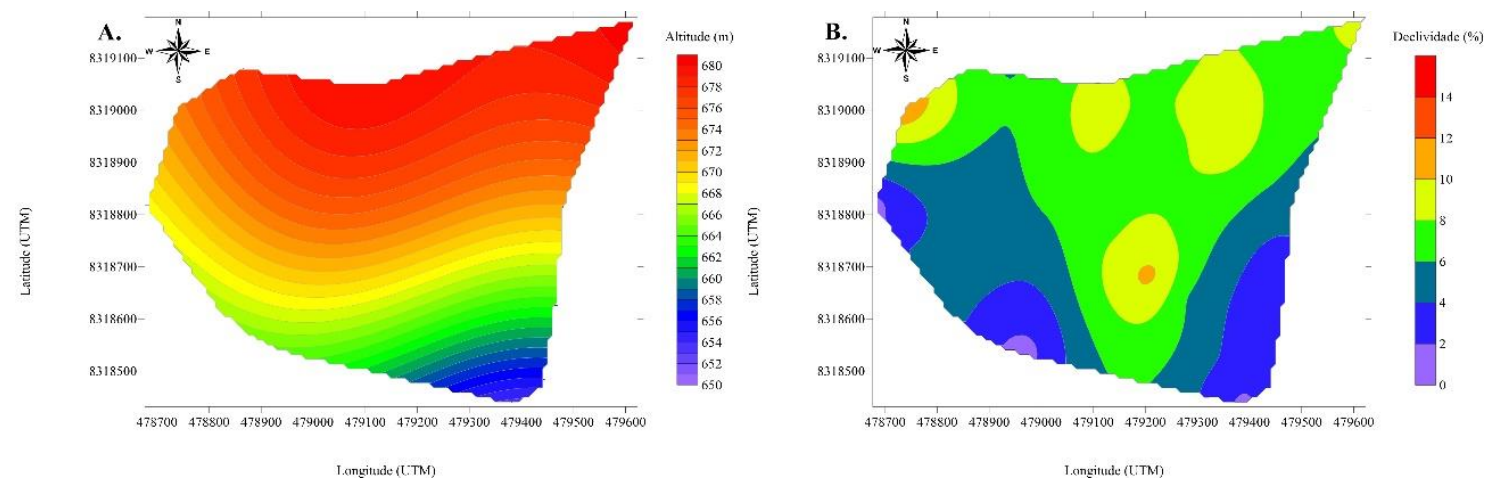

Em relação ao relevo foram ajustados os mapas referentes à altitude (ALT) e declividade (DEC) (Figura 2A e 2B). A caracterização do relevo em uma área de interesse é importante, pois esse fator tem marcante influência na dinâmica do escoamento superficial resultante do excedente hídrico resultante das precipitações que incidem sobre o terreno, de tal forma, impactando na erosão do solo.

Conforme se verifica na Figura 2A, as maiores declividades localizam-se nas áreas mais elevadas da microbacia, de maneira geral nas regiões mais ao norte, o que pode ser um fator que esteja contribuindo para incremento nas taxas de erosão na microbacia, uma vez que dada a alta friabilidade do solo, as áreas à montante podem contribuir com o transporte de material das partes mais altas para as partes mais baixas na paisagem, especialmente as veredas.

Souza et al. (2003) relatam que a pedoforma do relevo exerce marcante influência na variabilidade dos atributos do solo, sobretudo em virtude da erosão diferenciada que pode ocorrer com a convergência de água e remoção de sedimentos intrínsecos a cada pedoforma, sendo verificado em seu trabalho que os maiores coeficientes de variação são encontrados na pedoforma côncava, com exceção dos teores de areia fina e muito fina e erodibilidade, de tal forma, concluiu que nem mesmo a erosão adicionou variabilidade espacial para as propriedades do solo na mesma magnitude do relevo. Sanchez et al. (2009) verificaram que as maiores perdas de solo, risco de erosão e potencial natural de erosão e menor espessura do solo ocorreram na pedoforma convexa, indicando forte dependência espacial com a forma do relevo. Esse autor verificou ainda que a pedoforma côncava proporcionou maior variabilidade espacial, demonstrando que a forma do relevo condiciona padrões diferenciados de variabilidade. 
Figura 3. Mapa dos atributos físicos do solo: A)Argila (ARG); B) Silte (SILTE); C) Areia total (AREIA); D) areia muito grossa (AMG); E) areia grossa (AG); F) areia média (AM); G) areia fina (AF) e; H) areia muito fina (AMF)em uma microbacia do rio Pandeiros, Várzea Bonita, Januária-MG. Fonte: Os autores.
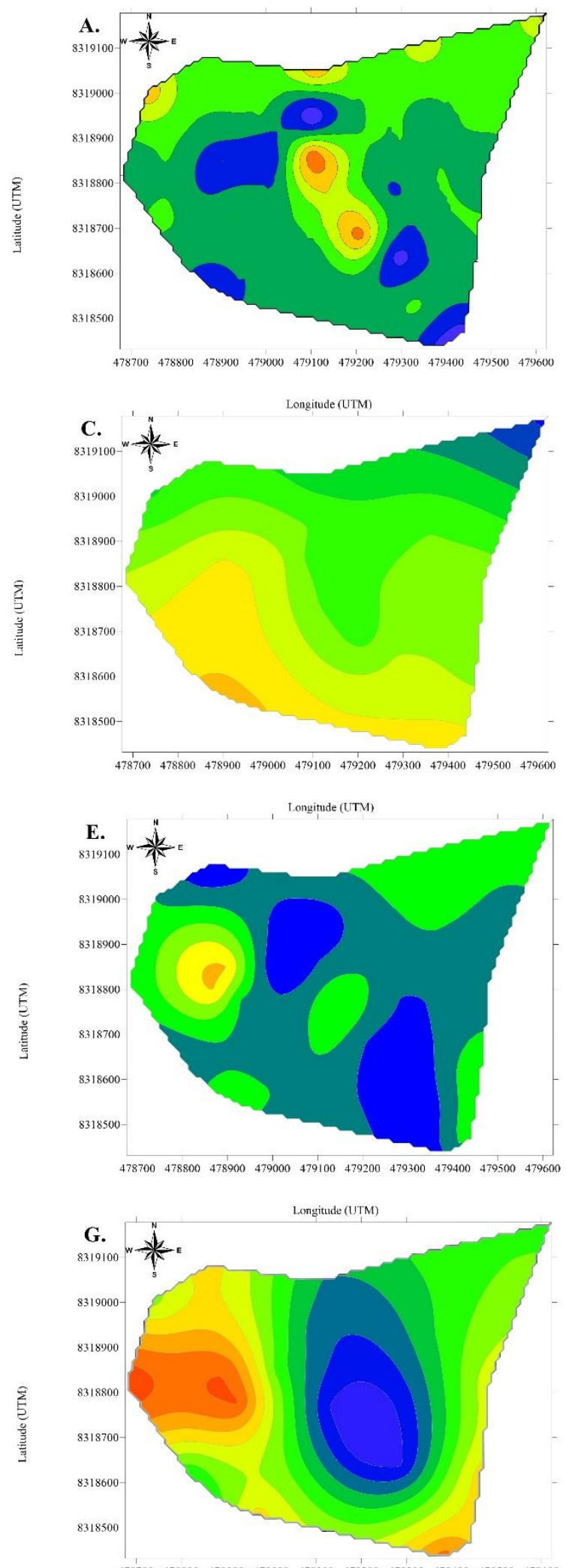

(angiude(vim)
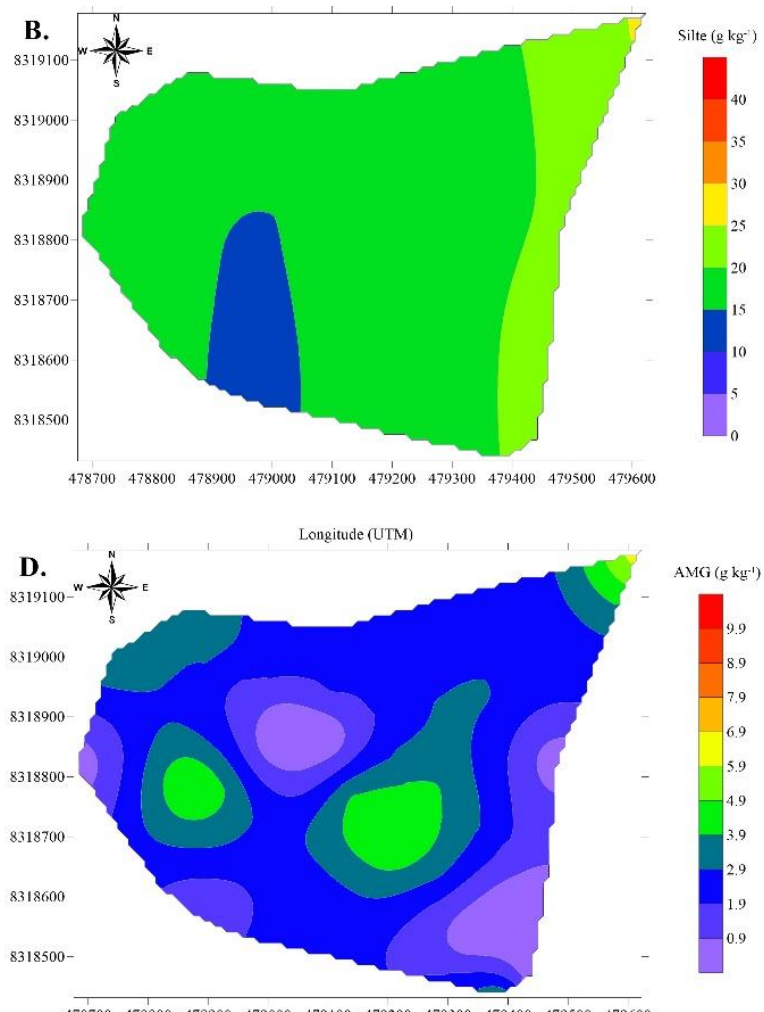

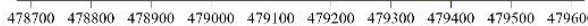
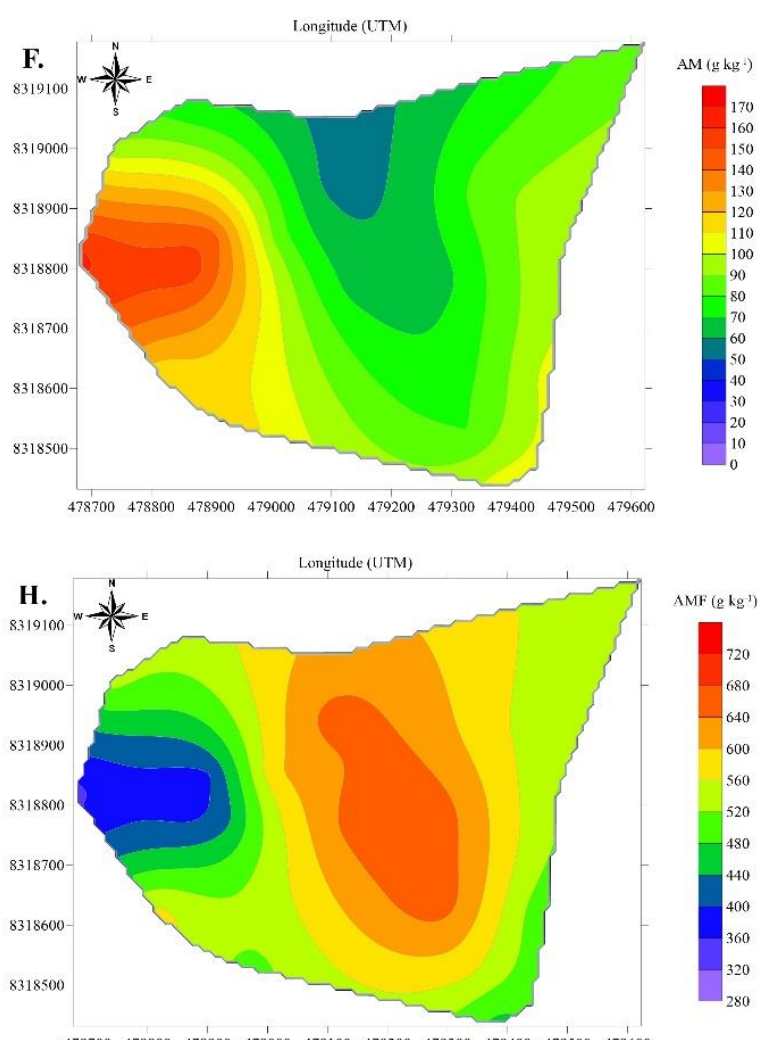

Longitude (UTM) 
Figura 4. Mapa dos atributos físicos do solo: A) densidade de partículas (DP); B) densidade do solo (DS); C) macroporosidade total (MAPT); D) microporosidade total (MIPT); E) volume total de poros $\left(\mathrm{VTP}_{\mathrm{d}}\right)$; $F$ ) condutividade hidráulica do solo saturado $\left.\left(\mathrm{K}_{\text {sat }}\right) ; \mathrm{G}\right)$ resistência a penetração (RP) e; $\mathrm{H}$ ) umidade do solo $(\Theta)$ em uma microbacia do rio Pandeiros, Várzea Bonita, Januária-MG. Fonte: Os autores.
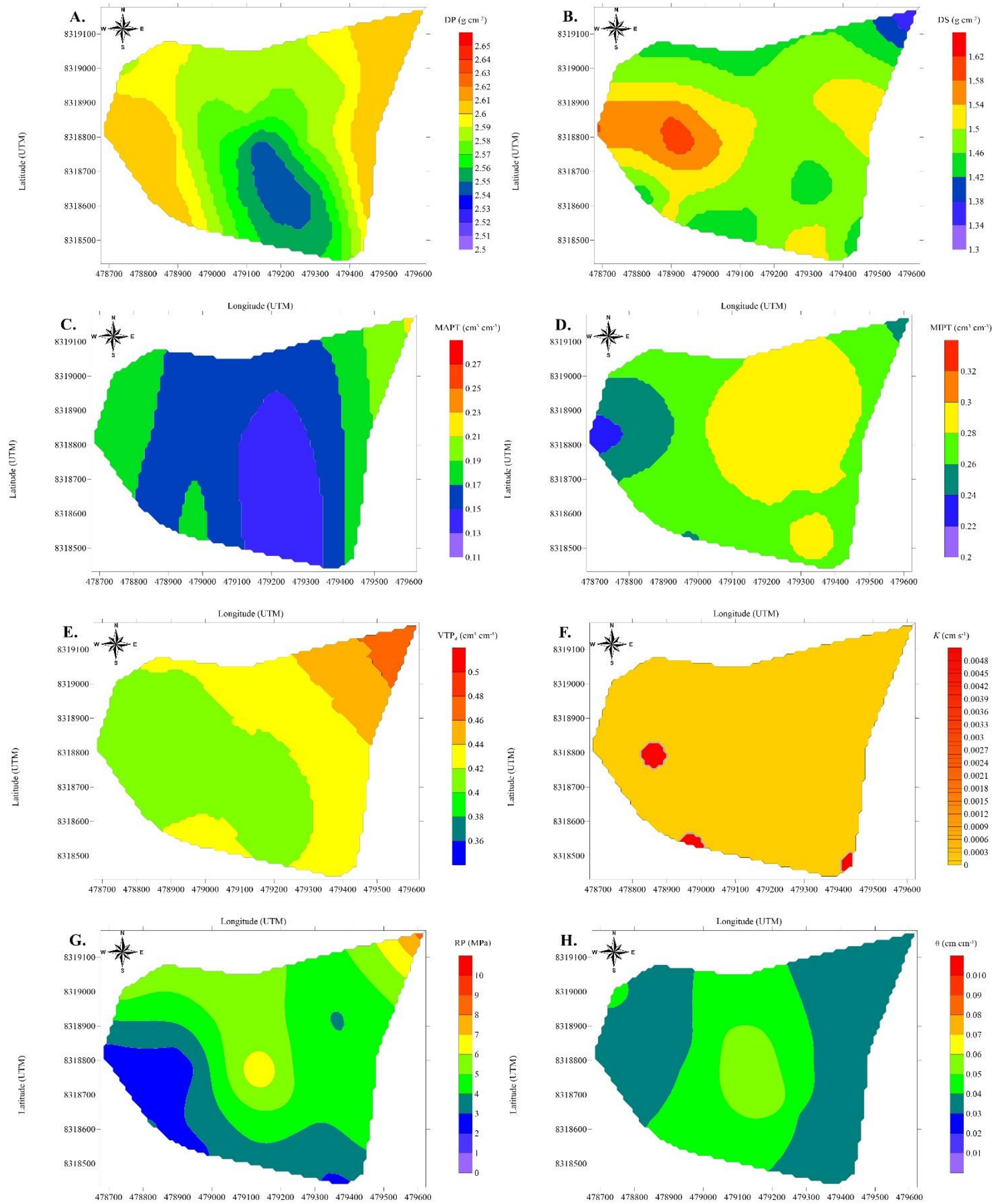
A inclinação do terreno é um fator que influencia fortemente as perdas de solo e água por erosão hídrica, pois, à medida que ela aumenta, maiores serão o volume e a velocidade do escoamento superficial e menor será a infiltração de água no solo. Com isso, aumenta a capacidade de transporte das partículas de solo pela enxurrada, assim como a própria capacidade desta de desagregar o solo por ação de cisalhamento, principalmente quando concentrada nos sulcos direcionados no sentido da declividade do terreno (COGO et al., 2003).

Lima et al. (2015) avaliando a variabilidade espacial de atributos físicos do solo em área de encosta sob processo de degradação, verificaram que a parte inferior da encosta caracteriza uma região de recebimento de sedimentos de diferentes granulometrias, mas ainda assim, sujeita ao processo de remoção, desta vez de partículas mais finas, por se tratar de uma área mais plana em que a velocidade de enxurrada não chega a ser suficiente para dar continuidade à remoção de sedimentos mais grosseiros (areia), ficando esse material depositado no local.

A granulometria do solo indicou predomínio da fração areia em relação as demais partículas, especialmente a fração areia muito fina (AMF). De acordo com o mapa de variabilidade explícito na figura 3A é possível verificar que os teores de argila (ARG) foram estimados entre 30 e $100 \mathrm{~g} \mathrm{~kg}^{-1}$, apresentando padrões bem heterogêneos quanto a sua distribuição. Os teores de silte (Figura 3B) foram estimados entre 0 e $25 \mathrm{~g} \mathrm{~kg}^{-1}$, apresentando padrões mais homogêneos na microbacia que os valores de argila (ARG) e os teores de areia total (AREIA), cujas estimativas variaram entre $885 \mathrm{e}$ $925 \mathrm{~g} \mathrm{~kg}^{-1}$.

Os teores de areia total (AREIA) apresentaram um padrão de incremento no sentido nordeste-sudoeste da microbacia (Figura 3C). Entre as frações de areia, o teor de areia muito grossa (AMG) apresentou estimativas entre 0 e $5,5 \mathrm{~g} \mathrm{~kg}^{-1}$ (Figura 3D), sem a ocorrência de padrões que permitissem claramente a identificação e associação do atributo a uma região específica. De maneira semelhante, sem a ausência de padrões homogêneos bem definidos, o teor de areia grossa (AG) apresentou estimativas variando de $2 \mathrm{a} \mathrm{g} \mathrm{kg}^{-1}$. As estimativas para os teores de areia média (AM), areia fina (AF) e areia muito fina (AMF) variaram respectivamente entre: 100-150, 160-340 e 320-640 g kg-1 (Figuras 3E, 3F e 3G). Para esses atributos foi possível observar padrões que permitiram a regionalização de valores mais baixos ou mais altos. Os mapas dos teores de areia média (AM) e areia fina (AF) indicaram maiores valores na região mais ao leste na microbacia, já os teores de areia muito fina (AMF) apresentaram maiores valores na região mais central no mapa.

A caracterização dos atributos referentes à granulometria do solo é importante por vários fatores, sendo aqueles relacionados à dinâmica de água no solo os mais expressivos, uma vez que mantidas constantes as demais propriedades do solo, o predomínio de frações mais finas e o incremento nos teores de silte podem promover diminuição da condutividade hidráulica do solo. No presente trabalho, foi verificada forte correlação negativa $\left(r=-0,80^{*}\right)$ entre a condutividade hidráulica do solo saturado (Ksat) e os teores de areia muito fina (AMF), de modo contrário, sendo verificada correlação significativa positiva para as frações $A G\left(r=0,44^{*}\right)$, AM $\left(r=0,63^{*}\right)$ e $A F\left(r=0,83^{*}\right)$, conforme se verifica na Tabela 3. 
Moraes et al. (2015) avaliando as perdas de solo por erosão hídrica laminar em pastagem sob condição de chuva natural em áreas de predomínio de Neossolo Quartzarênico verificaram que a maior desagregação e mobilização de partículas de solo ocorreram nas parcelas constituídas com maior proporção de areia fina em relação às demais frações das partículas no solo. Por sua vez, o predomínio de frações mais grosseiras em detrimento aos de partículas de menor diâmetro, principalmente a argila, condicionará menor retenção de água no solo, em virtude da menor área superficial específica e menor capilaridade (LUCIANO et al., 2012; DONAGEMMA et al., 2016). Situação essa que pode ser um entrave para o manejo do solo, especialmente na adoção de medidas que tenham como enfoque o plantio de espécies para recomposição da cobertura vegetal.

Tabela 3. Coeficientes de correlação de Spearman entre atributos físicos do solo e relevo em uma microbacia do rio Pandeiros. Fonte: Os autores.

\begin{tabular}{cccccccccc}
\hline & ALT & DEC & ARG & SILTE & AREIA & AMG & AG & AM & AF \\
\hline DEC & $0,66^{*}$ & -- & -- & -- & -- & -- & -- & -- & -- \\
ARG & 0,35 & $0,54^{*}$ & -- & -- & -- & -- & -- & -- & -- \\
SILTE & 0,12 & 0,16 & 0,00 & -- & -- & -- & -- & -- & -- \\
AREIA & $-0,34$ & $-0,54^{*}$ & $-0,87^{*}$ & $-0,45^{*}$ & -- & -- & -- & -- & -- \\
AMG & 0,26 & $0,48^{*}$ & 0,17 & 0,15 & $-0,19$ & -- & -- & -- & -- \\
AG & 0,11 & $-0,08$ & 0,06 & 0,18 & $-0,12$ & 0,16 & -- & -- & -- \\
AM & $-0,37$ & $-0,54^{*}$ & $-0,26$ & $-0,12$ & 0,31 & 0,05 & $0,58^{*}$ & -- & -- \\
AF & $-0,32$ & $-0,65^{*}$ & $-0,23$ & $-0,26$ & 0,30 & $-0,12$ & 0,36 & $0,73^{*}$ & -- \\
AMF & 0,29 & $0,55^{*}$ & 0,12 & 0,15 & $-0,18$ & 0,02 & $-0,54^{*}$ & $-0,85^{*}$ & $-0,95^{*}$ \\
VTPd & 0,07 & 0,13 & 0,04 & 0,11 & $-0,12$ & $-0,16$ & 0,12 & $-0,22$ & $-0,08$ \\
MAPT & $-0,02$ & $-0,11$ & $-0,03$ & 0,25 & $-0,08$ & $-0,04$ & 0,36 & 0,17 & 0,31 \\
MIPT & 0,08 & 0,31 & 0,12 & $-0,18$ & $-0,08$ & $-0,16$ & $-0,29$ & $-0,47^{*}$ & $-0,51^{*}$ \\
DS & $-0,04$ & $-0,25$ & $-0,15$ & $-0,33$ & 0,30 & $-0,14$ & 0,09 & $0,40^{*}$ & 0,39 \\
DP & $-0,13$ & $-0,46^{*}$ & $-0,26$ & 0,13 & 0,15 & $-0,24$ & 0,32 & $0,44^{*}$ & $0,45^{*}$ \\
Ksat & $-0,37$ & $-0,55^{*}$ & $-0,36$ & $-0,18$ & 0,38 & $-0,12$ & $0,44^{*}$ & $0,63^{*}$ & $0,83^{*}$ \\
RP & $0,62^{*}$ & $0,74^{*}$ & $0,54^{*}$ & 0,34 & $-0,60^{*}$ & 0,15 & $-0,13$ & $-0,64^{*}$ & $-0,64^{*}$ \\
$\boldsymbol{\theta}$ & $0,44^{*}$ & 0,39 & $0,48^{*}$ & 0,01 & $-0,36$ & 0,13 & $-0,06$ & $-0,31$ & $-0,50^{*}$ \\
\hline & AMF & $\mathbf{V T P d}$ & $\mathbf{M A P T}$ & $\mathbf{M I P T}$ & $\mathbf{D S}$ & $\mathbf{D P}$ & $\mathbf{K s a t}$ & $\mathbf{R P}$ & \\
\hline VTPd & 0,10 & -- & -- & -- & -- & -- & -- & -- & \\
MAPT & $-0,34$ & 0,62 & -- & -- & -- & -- & -- & -- & \\
MIPT & $0,55^{*}$ & 0,01 & $-0,72^{*}$ & -- & -- & -- & -- & -- & \\
DS & $-0,40^{*}$ & $-0,72$ & $-0,54^{*}$ & 0,16 & -- & -- & -- & -- & \\
DP & $-0,49^{*}$ & 0,21 & $0,44^{*}$ & $-0,34$ & 0,08 & -- & -- & -- & \\
Ksat & $-0,80^{*}$ & 0,29 & $0,57^{*}$ & $-0,51^{*}$ & 0,05 & $0,54^{*}$ & -- & -- & \\
RP & $0,57^{*}$ & 0,33 & 0,12 & 0,16 & $-0,45^{*}$ & $-0,31$ & $-0,50^{*}$ & -- & \\
$\boldsymbol{\theta}$ & 0,39 & $-0,14$ & $-0,41^{*}$ & 0,39 & 0,02 & $-0,27$ & $-0,69^{*}$ & 0,35 & \\
\hline
\end{tabular}

Atributos Avaliados: Altitude (ALT), declividade (DEC), argila (ARG), silte (SILTE), areia total (AREIA), areia muito grossa (AMG), areia grossa (AG), areia média (AM), areia fina (AF), areia muito fina (AMF), volume total de poros determinado (VTPd), macroporosidade (MAPT), microporosidade (MIPT), densidade do solo (DS), densidade de partículas (DP), condutividade hidráulica do solo saturado (Ksat), resistência do solo à penetração (RP) e umidade do solo $(\Theta)$. Significativo ao nível de $5 \%$ pelo teste $t(*)$.

A densidade de partículas (DP) foi o segundo atributo com menor coeficiente de variação (CV) na microbacia, sendo estimados valores entre 2,54 e 2,6 g cm${ }^{-3}$, o padrão de regionalização dos maiores valores foram encontrados nas 
extremidades do mapa, sendo os menores valores verificados nas áreas mais centrais e ao sul na microbacia (Figura 4A). Eguchi et al. (2002) avaliando a variabilidade espacial densidade de partículas em um solo aluvial no Município de LavrasMG não conseguiram ajustar um modelo de semivariograma que explicasse a variabilidade espacial do atributo, devido à tendência de o fenômeno apresentar efeito pepita puro ou ausência total de dependência espacial. Vários trabalhos demonstram que a densidade de partículas é um atributo do solo com baixa variabilidade, aproximando os seus valores próximos aos do próprio material de origem do solo (CAMPOS et al., 2013; CERESOLI et al., 2016; FERREIRA et al., 2016a).

A partir da visualização (Figura 4B) do mapa de densidade do solo (DS) é possível verificar um padrão com maiores valores de DS na região oeste da microbacia. De acordo com Luciano et al. (2012), a DS aumenta com o teor de areia total e areia fina e reduz com os teores de argila. No presente trabalho, a densidade do solo apresentou correlação positiva $\left(r=0,4^{*}\right)$ com o teor de areia média (AM) e correlação negativa $\left(r=-0,4^{*}\right)$ com o teor de areia muito fina (AMF), de tal forma, apresentando semelhanças nos respectivos mapas de variabilidade, já apresentados anteriormente (Figuras 3F e 3H). Qiao et al (2018) verificaram uma forte dependência espacial para a densidade do solo, mencionando ser um importante parâmetro físico para estimar as reservas de carbono $(\mathrm{C})$ e nutrientes $(\mathrm{N})$ no solo e para simular processos hidráulicos, estando ainda correlacionado com os teores de areia, silte e argila. De acordo com Ribeiro et al. (2016), a forma de preparo do solo contribui para alterações da densidade do solo, verificando em seu trabalho que o sistema de plantio direto torna o solo mais denso, e menos poroso que os sistemas de plantio convencional, porém, favorecendo a conservação da umidade.

Para a condutividade hidráulica do solo saturado (Ksat) não foi possível um ajuste de um modelo adequado para explicar a variabilidade dos dados, com $r^{2}$ tendendo a zero (tabela 2), o que indica forte tendência para se atingir o efeito pepita puro, isto é, significa que o alcance da dependência espacial para o atributo em questão é menor que o menor espaçamento entre amostras (VIEIRA, 2000). Nesse caso, a utilização da estatística clássica seria mais apropriada, o que inclui a própria média $\left(0,0028 \mathrm{~cm} \mathrm{~s}^{-1}\right)$ obtida no presente trabalho. Para fins elucidativos construiu-se o mapa desse atributo, todavia, as estimativas apresentaram praticamente um mesmo valor para toda a microbacia, conforme observa-se (Figura 4F).

Silva e Kato (1997) reportam que os valores de Ksat são bem maiores no local onde ainda prevalece a cobertura natural do solo, estando fortemente correlacionada com MAPT, uma vez que pequenas reduções na MAPT promovem grandes reduções nos valores de Ksat, correlação que se verifica neste trabalho $\left(r=0,57^{*}\right)$ (Tabela 03). Oliveira Júnior et al. (2014) mostraram que o uso do solo com pastagem alterou significativamente a variabilidade espacial da condutividade hidráulica do solo saturado quando comparadas com as do solo com caatinga, atribuindo essas modificações ao pisoteio animal.

Em relação à macroporosidade do solo (MAPT) as estimativas foram de 0,13 a $0,27 \mathrm{~cm}^{3} \mathrm{~cm}^{-3}$, cuja distribuição indicou menores valores nas áreas centrais (Figura 4C), entre 0,13 e 0,15 $\mathrm{cm}^{3} \mathrm{~cm}^{-3}$. Segundo Kiehl (1979), os solos agrícolas não devem apresentar valores menores que $0,10 \mathrm{~cm}^{3} \mathrm{~cm}^{-3}$ de MAPT. Os limites verificados para a 
microporosidade do solo (MIPT) foram estimados entre 0,22 e $0,28 \mathrm{~cm}^{3} \mathrm{~cm}^{-3}$, com maiores valores nas áreas mais centrais do mapa da microbacia (Figura 4D). Kamimura et al. (2013) avaliando a variabilidade espacial de atributos físicos de um Latossolo Vermelho-Amarelo sob lavoura cafeeira encontraram valores de MIPT variando de 0,40 a $0,45 \mathrm{~cm}^{3} \mathrm{~cm}^{-}$

${ }^{3}$ nas profundidades de 0 a $0,13 \mathrm{~m}$. Os valores de volume total de poros (VTPd) variaram de $0,41 \mathrm{a} 0,46 \mathrm{~cm}^{3} \mathrm{~cm}^{-3}$, com incremento no sentido das regiões centrais para a região nordeste da microbacia (Figura 4E). As características mais influenciadas pela porosidade do solo são a permeabilidade de água no solo e a aeração, que uma vez reduzidas a níveis críticos, podem comprometer a capacidade de desenvolvimento das culturas (KLEIN et al., 2008; GUBIANI et al., 2013) e contribuir para ocorrência de erosão em virtude do aumento do escoamento superficial (BRANDÃO et al., 2007; SPOHR et al., 2009).

O mapeamento da resistência do solo à penetração (RP) indicou variação de 2 a 7 MPa na microbacia. Os maiores valores observados para esse atributo foram distribuídos em duas regiões distinguíveis no mapa ilustrado na figura 4G, sendo uma área na porção mais central e outro na extremidade nordeste da microbacia. Em ambas as regiões que foram estimados os maiores valores de RP constatou-se a presença de afloramentos rochosos, que podem ter contribuído para os incrementos observados. A resistência do solo a penetração, quando em valores elevados, além do efeito restritivo ao crescimento vegetal, pode contribuir para redução da qualidade física do solo por estar associada à ocorrência de solos rasos. Nessa condição, a presença de uma camada de impedimento subsuperficial torna mais fácil o deslocamento de grandes massas de solo, sobretudo quando a umidade do solo excede a capacidade de campo (ARAÚJO et al., 2007; IORI et al., 2012). De acordo Valicheski et al. (2012) valores críticos de RP variam de 1,5 a 4,0 MPa, conforme o tipo de solo e a espécie vegetal sendo, em geral, o valor de 2,0 MPa é aceito como impeditivo ao crescimento radicular.

O mapeamento da umidade do solo para a bacia considerada indicou variação da umidade do solo ( $(\Theta)$ entre 0,04 e $0,06 \mathrm{~cm}^{3} \mathrm{~cm}^{-3}$ (Figura, $4 \mathrm{H}$ ). Apesar de ser um parâmetro efêmero, ou seja, podendo apresentar variações consideráveis ao longo do tempo em um mesmo ponto de coleta, a umidade do solo pode indicar zonas com maior potencial de armazenamento de água no solo, o que pode ter relação com outros atributos do solo, especialmente os teores de matéria orgânica do solo (SAMPAIO et al., 2010). Nesse caso, seria possível, por exemplo, o estabelecimento de projetos de recomposição da cobertura vegetal, alocando-se as espécies selecionadas de acordo com seu potencial de sobrevivência em diferentes condições hídricas do solo, ou, adotando-se estratégias para maximizar a umidade do solo nos locais de baixa capacidade de retenção, tal como a incorporação de fontes de matéria orgânica de forma pontual conforme a demanda, como o plantio de espécies florestais em covas.

A análise multivariada dos dados indicou que o componente principais 1 (CP1) e 2 (CP2) explicaram respectivamente $91,51 \%$ e 4,21\% da variabilidade dos dados da microbacia, ou seja, 95,72\% da variabilidade acumulada dos atributos avaliados. Segundo Sabino et al. (2014) a análise de componentes principais é a técnica multivariada mais utilizada para explorar, interpretar e reduzir os dados, sem que haja perda de informação. Neste caso, os autovalores, autovetores e matrizes de correlação e covariância são determinados por cálculos robustos não sujeitos à influência de 
outliers, os componentes principais (CP) obtidos constituem as novas variáveis respostas e são utilizadas nas análises subsequentes do estudo de modo que a interpretação de cada CP é baseada nas variáveis que mais contribuem para a CP. Esses autores utilizando métodos estatísticos robustos na análise ambiental de dados da bacia do rio das Velhas-MG, verificaram que a análise de componentes principais detectou as variáveis que mais contribuem para a degradação da qualidade das águas do rio das Velhas e a visualização espacial dos escores mostrou onde a contaminação está mais evidente.

No presente trabalho os atributos que apresentaram maior correlação com os CP1 foram os teores de areia média $(r=0,908)$, areia fina $(r=0,96)$ e areia muito fina $(r=0,997)$, conforme se verifica na figura 5. Os CP2 apresentaram maiores correlações com os teores de argila $(r=0,718)$ e os teores de areia total $(r=0,776)$. Observa-se que a maior parte da variabilidade dos dados na microbacia foi explicada pelos atributos que apresentaram correlação com os CP1, de tal modo, poderiam ser interpretados como os mais sensíveis para demonstrar a heterogeneidade da bacia, podendo essas variações estarem associadas com os processos formacionais atuantes, mas também podendo estar relacionadas com as ações antrópicas que decorreram no ambiente. Nesse contexto, o monitoramento de tais atributos é imprescindível no conhecimento de áreas mais problemáticas no aspecto da erosão, com a possibilidade de estabelecimento de zonas de manejo específicas, racionalizando os recursos.

Figura 5. Correlação entre atributos do solo, relevo e os componentes principais em uma microbacia do rio Pandeiros, Várzea Bonita, Januária-MG. Fonte: Os autores.

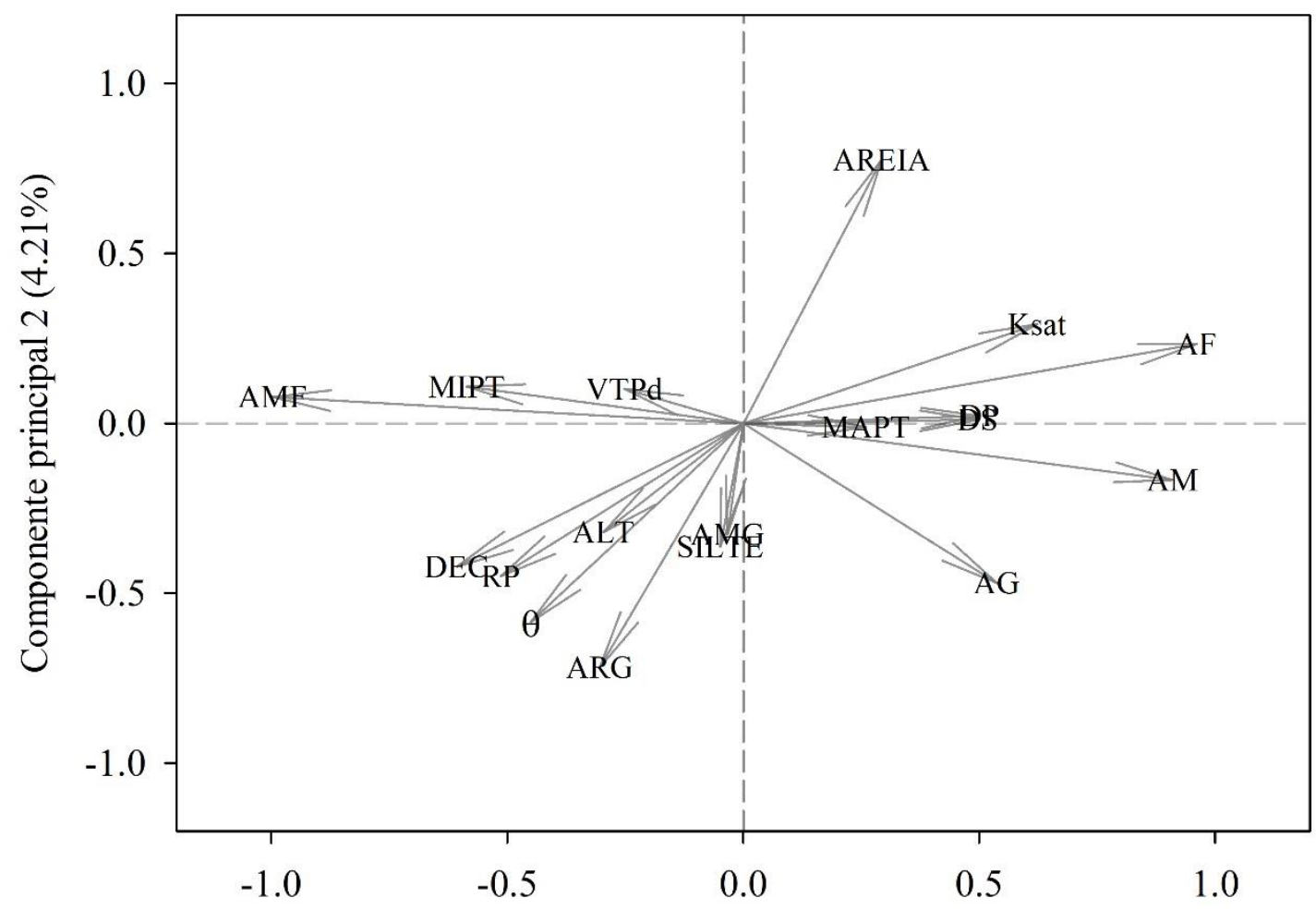

Componente principal $1(91.51 \%)$ 
Na figura 6 é possível verificar o mapa de variabilidade dos scores dos CP1, sendo possível visualizar semelhanças notáveis com as figuras que contém os mapas dos respectivos atributos os quais apresentaram correlações altas. Alves et al. (2014) verificaram que 78,11\% da variabilidade total existente no conjunto de variáveis originais foi expressa pelos componentes principais 1 e 3, mencionando que a análise do mapa dos componentes principais poderia simplificar a interpretação dos demais atributos. José et al. (2013) verificaram que a análise de componentes principais associada a geoestatística, permitiu reduzir de treze variáveis físicohídricas do solo para apenas duas novas variáveis, que foram: porosidade do solo e taxa de infiltração, as quais explicaram $78,40 \%$ da variação dos dados.

Figura 6. Mapa dos escores dos componentes principais (CP1) em uma microbacia do rio Pandeiros, Várzea Bonita, Januária-MG. Fonte: Os autores.

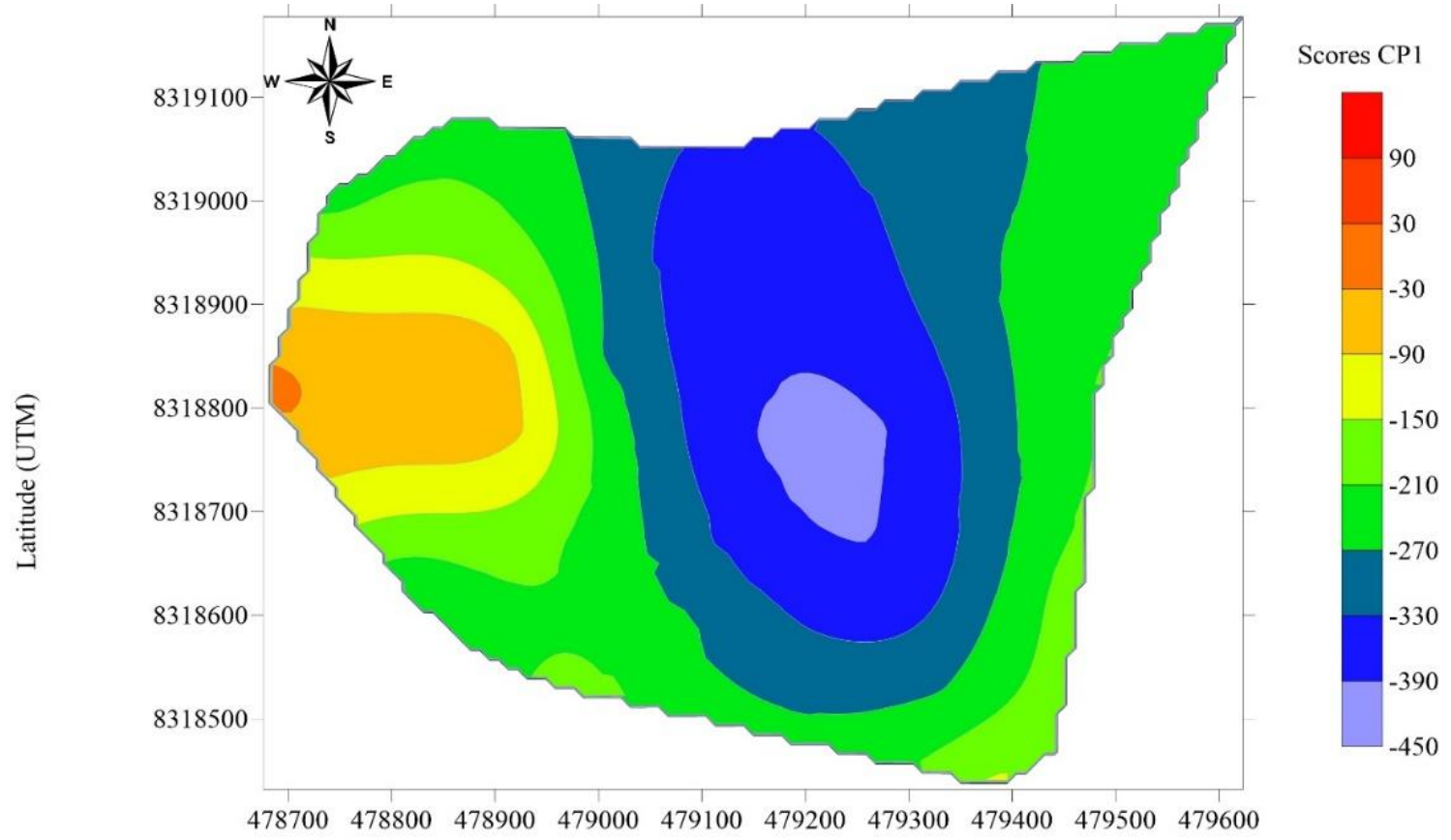

Longitude (UTM)

\section{CONCLUSÕES}

O mapeamento do solo na microbacia em estudo indica dependência espacial para a maioria dos atributos físicos do solo, com exceção da condutividade hidráulica do solo saturado.

A análise multivariada dos atributos físicos do solo baseada nos componentes principais fornece componentes que representam a variabilidade dos dados na microbacia, possibilitando delimitar atributos mais sensíveis no monitoramento das modificações ocorridas no solo. 
Os teores de areia média, areia fina e areia muito fina são os atributos que mais refletem as modificações ocorridas no solo.

\section{AGRADECIMENTOS}

Realizado com apoio da Fundação de Amparo à Pesquisa do Estado de Minas Gerais - FAPEMIG, Processo N.: CAG - APQ-03775-14, Projeto: "Quantificação, monitoramento e controle da erosão na bacia do rio Pandeiros".

O presente trabalho foi realizado com apoio da Coordenação de Aperfeiçoamento de Pessoal de Nível Superior - Brasil (CAPES) - Código de Financiamento 001.

\section{REFERENCES}

ALVES, S. M. DE F.; QUEIROZ, D. M. DE; ALCÂNTARA, G. R. DE; REIS, E. F. DOS. Variabilidade espacial de atributos físico-químicos do solo usando técnicas de análise de componentes principais e geoestatística. Bioscience Journal, v. 30, n. 3, p. 22-30, 2014.

ARAÚJO, R.; GOEDERT, W. J.; PINTO COELHO LACERDA, M. Qualidade de um solo sob diferentes usos e sob cerrado nativo. Revista Brasileira de Ciência do solo, Viçosa, v. 31, n. 5, p. 1099-1108, 2007.

BRANDÃO, V. dos S.; SILVA, D. D. da; RUIZ, H. A.; PRUSKI, F. F.; SCHAEFER, C. E. G. R.; MARTINEZ, M. A.; SILVA, E. O. Perdas de solo e caracterização física e micromorfológica de crostas formadas em solos sob chuva simulada. Engenharia Agrícola, Jaboticabal, v. 27, n. 1, p. 129-138, 2007.

BHUNIA, G. S.; SHIT, P. K.; CHATTOPADHYAY, R. Assessment of spatial variability of soil properties using geostatistical approach of lateritic soil (West Bengal, India). Annals of Agrarian Science, Georgia, v. 16, n. 4, p. 436-443, 2018.

BUENO, C. R. P.; ARRAES, C. L.; PEREIRA, G. T.; CORA, J. E.; CAMPOS, S. Análise multivariada na determinação do risco de erosão em solos sob irrigação. Irriga, v. 15, n. 1, p. 23, 2018.

CAMBARDELLA, C.; MOORMAN, T.; PARKIN, T.; KARLEN, D.; NOVAK, J.; TURCO, R.; KONOPKA, A. Field-scale variability of soil properties in central lowa soils. Soil Science Society of America journal, Madison, v. 58, n. 5, p. 1501-1511, 1994.

CAMPOS, M. C. C.; OLIVEIRA, I. A. DE; AQUINO, R. E. DE; BERGAMIN, A. C.; SILVA, D. A. P. DA. Distribuição espacial de atributos físicos do solo em área cultivada com cana-de-açúcar. Revista Agro@mbiente On-line, v. 7, n. 2, p. 119-128, 2013.

CERESOLI, L. L.; SOBENKO, L.; KREITLOV, B.; ARMINDO, R. Variabilidade espacial dos atributos físico-hidráulicos do solo em uma área e estimativa da lâmina de irrigação de precisão. Irriga, v. 1, n.1, p. 179-190, 2016.

CERRETELLI, S.; POGGIO, L.; GIMONA, A.; YAKOB, G.; BOKE, S.; HABTE, M.; COULL, M.; PERESSOTTI, A.; BLACK, H. Spatial assessment of land degradation through key ecosystem services: The role of globally available data. Science of The Total Environment, v. 628629 , p. 539-555, 2018.

COGO, N. P.; LEVIEN, R.; SCHWARZ, R. A. Perdas de solo e água por erosão hídrica influenciadas por métodos de preparo, classes de declive e níveis de fertilidade do solo. Revista Brasileira de Ciência do Solo, Viçosa, v. 27, n. 4, p. 743-753, 2003.

CORÁ, J. E.; BERALDO, J. M. G. Variabilidade espacial de atributos do solo antes e após calagem e fosfatagem em doses variadas na cultura de cana-de-açúcar. Engenharia Agrícola, Jaboticabal, v. 26, n. 2, p. 374-387, 2006.

CORADO NETO, F. da C.; SAMPAIO, F. de M. T.; VELOSO, M. E. da C.; MATIAS, S. S. R.; ANDRADE, F. R.; LOBATO, M. G. R. Variabilidade Espacial da Resistência à Penetração em Neossolo Litólico Degradado. Revista Brasileira de Ciência do Solo, Viçosa, v. 39, n. 5, p. 1353-1361, 2015. 
DONAGEMMA, G. K.; FREITAS, P. L. DE; CARVALHO BALIEIRO, F. DE; FONTANA, A.; SPERA, S. T.; LUMBRERAS, J. F.; VIANA, J. H. M.; ARAÚJO FILHO, J. C. DE; SANTOS, F. C. DOS; ALBUQUERQUE, M. R. DE. Caracterização, potencial agrícola e perspectivas de manejo de solos leves no Brasil. Pesquisa Agropecuária Brasileira, v. 51, n. 9, p. 1003-1020, 2016.

EGUCHI, E. S.; SILVA, E. L. DA; OLIVEIRA, M. S. DE. Variabilidade espacial da textura e da densidade de partículas em um solo aluvial no Município de Lavras, MG. Revista Brasileira de Engenharia Agrícola e Ambiental, v. 6, n. 2, p. 242-246, 2002.

EMPRESA BRASILEIRA DE PESQUISA AGROPECUÁRIA (EMBRAPA). Centro Nacional de Pesquisas de Solos. Manual de métodos de análise de solo. 3.ed. Rio de Janeiro: Embrapa Solos. 2017. 574 p.

FARACO, M. A.; URIBE-OPAZO, M. A.; SILVA, E. A. A. DA; JOHANN, J. A.; BORSSOI, J. A. Seleção de modelos de variabilidade espacial para elaboração de mapas temáticos de atributos físicos do solo e produtividade da soja. Revista Brasileira de Ciência do Solo, v. 32 , n. 2, p. 463-476, 2008.

FERREIRA, L. L. N.; FILHO, L. C. DE A. L.; TORRES, M. M.; OLIVEIRA JÚNIOR, R. F. DE; VALE, C. N. C. DO; FRANCO, M. S. DE B. P. Spatial variability of available water and micro-sprinkler irrigation in cambisol. Revista Ceres, v. 63, n. 6, p. 782-788, 2016a.

FERREIRA, V. G. ; ALVES, P. F. S. ; SANTOS, S. R. ; OLIVEIRA, H. F. A. ; SILVA, R. F. ; KONDO, M. K. . Calibração de Sonda de Reflectometria no Tempo (TDR) para medida da umidade do solo na bacia do rio Pandeiros - MG. In: Anais do 10 FÓRUM ENSINO PESQUISA EXTENSAO GESTÃO - FEPEG, 2016, Montes Claros - MG. Responsabilidade social: Indissociabilidade ensino, pesquisa e extensão universitária, 2016b.

GS+: Geostatistics for environmental sciences. 7th.ed. Plainwell: Gamma Design Software; 2004.

GOLDEN SOFTWARE. Surfer for Windows, version 13.0: Software de geração de mapas de contorno e superfícies contínuas. Colorado, 2016.

GOMES, N. M.; SILVA, A. M. da; MELLO, C. R. de; FARIA, M. A. de; OLIVEIRA, P. M. de. Métodos de ajuste e modelos de semivariograma aplicados ao estudo da variabilidade espacial de atributos físico-hídricos do solo. Revista Brasileira de Ciência do Solo, v. 31, n.3, p. 435-443, 2007.

GREGO, C. R.; VIEIRA, S. R. Variabilidade espacial de propriedades físicas do solo em uma parcela experimental. Revista Brasileira de Ciência do Solo, v. 29, n. 2, p. 169-177, 2005.

GROSSMAN, R.; REINSCH, T. 2.1 Bulk density and linear extensibility. Methods of Soil Analysis: Part 4 Physical Methods, $\mathrm{n}$. methodsofsoilan4, p. 201-228, 2002.

GUBIANI, P. I.; REICHERT, J. M.; REINERT, D. J. Indicadores hídrico-mecânicos de compactação do solo e crescimento de plantas. Revista Brasileira de Ciência do Solo, v. 37, n. 1, p. 1-10, 2013.

GUEDES, L. P. C.; URIBE-OPAZO, M. A.; JOHANN, J. A.; SOUZA, E. G. DE. Anisotropia no estudo da variabilidade espacial de algumas variáveis químicas do solo. Revista Brasileira de Ciência do Solo, v. 32, n. 6, p. 2217-2226, 2008.

IORI, P.; DIAS JUNIOR, M. de S.; DA SILVA, R. B. Resistência do solo à penetração e ao cisalhamento em diversos usos do solo em áreas de preservação permanente. Bioscience Journal, Uberlândia, v. 28, n. 1, p. 185-195, 2012.

JOSÉ, J. V.; REZENDE, R.; FREITAS, P.; HONGYU, K.; PERBONI, A.; MARQUES, P. A. A.; DIAS, C.; COELHO, R. D. Análise multivariada e geoestatística de variáveis físico-hídricas de diferentes solos. Water Resources and Irrigation Management, v. 2, n. 3, p. 121-129, 2013.

KAMIMURA, K. M.; SANTOS, G. R. DOS; OLIVEIRA, M. S. DE; DIAS JUNIOR, M. DE S.; GUIMARÃES, P. T. G. Variabilidade espacial de atributos físicos de um LatossoloVermelho-Amarelo, sob lavoura cafeeira. Revista Brasileira de Ciência do Solo, v. 37, n. 4, p. 877888, 2013.

KIEHL, E.L. Manual de edafologia. São Paulo, Ceres, 1979. 262p.

KLEIN, V. A.; VIEIRA, M. L.; DURIGON, F. F.; MASSING, J. P.; FÁVERO, F. Porosidade de aeração de um Latossolo Vermelho e rendimento de trigo em plantio direto escarificado. Ciência Rural, v. 38, n. 2, p. 365-371, 2008.

LIMA, F. V. D.; SILVINO, G. D. S.; MELO, R. S. D. S.; LIRA, E. C.; RIBEIRO, T. D. S. Variabilidade espacial de atributos físicos do solo em área de encosta sob processo de degradação. Revista Caatinga, v. 28, n. 4, p. 53-63, 2015.

LUCIANO, R. V.; ALBUQUERQUE, J. A.; COSTA, A. DA; BATISTELLA, B.; WARMLING, M. T. Atributos físicos relacionados à compactação de solos sob vegetação nativa em região de altitude no Sul do Brasil. Revista Brasileira de Ciência do Solo, v. 36, n. 6, p. 1733-1744, 2012. 
MACHADO, L. de O.; LANA, Â. M. Q.; LANA, R. M. Q.; GUIMARÃES, E. C.; FERREIRA, C. V. Variabilidade espacial de atributos químicos do solo em áreas sob sistema plantio convencional. Revista Brasileira de Ciência do Solo, Viçosa, v. 31, n. 3, p. 591-599, 2007.

MARCHETTI, A.; PICCINI, C.; FRANCAVIGLIA, R.; MABIT, L. Spatial Distribution of Soil Organic Matter Using Geostatistics: A Key Indicator to Assess Soil Degradation Status in Central Italy. Pedosphere, Najing, v. 22, n. 2, p. 230-242, 2012.

MIQUELONI, D. P.; GIANELLO, E. M.; BUENO, C. R. P. Variabilidade espacial de atributos e perda de solo na definição de zonas de manejo. Pesquisa Agropecuária Tropical, Goiânia, v. 45, n. 1, p. 18-28, 2015.

MORAES, I. C.; CORRÊA, E. A.; COUTO JR, A.; PINTO, S. dos A. F. Análise das perdas de solo de parcelas experimentais em pastagens no centro leste paulista, 2015. Disponível em: <https://eventosolos.org.br/cbcs2015/arearestrita/arquivos/1764.pdf >. Acesso em: 23 ago. 2018.

MORAES, S. O.; LIBARDI, P. L.; REICHARDT, K.; BACCHI, O. O. S. Heterogeneidade dos pontos experimentais de curvas de retenção da água no solo. Scientia Agricola, v. 50, n. 3, p. 393-403, 1993.

OLIVEIRA JÚNIOR, J. A. S. DE; SOUZA, E. S. DE; CORREA, M. M.; LIMA, J. R. DE S.; SOUZA, R. M. S.; SILVA FILHO, L. A. DA. Variabilidade espacial de propriedades hidrodinâmicas de um Neossolo Regolítico sob pastagem e caatinga. Revista Brasileira de Engenharia Agrícola e Ambiental, v. 18, n. 6, p. 631-639, 2014.

PAZINI, J. DE B.; BOTTA, R. A.; SEIDEL, E. J.; SILVA, F. F. DA; MARTINS, J. F. DA S.; BARRIGOSSI, J. A. F.; RÜBENICH, R. Geostatistics applied to the study of the spatial distribution of Tibraca limbativentris in flooded rice fields. Ciência Rural, v. 45, n. 6, p. 1006-1012, 2015.

PICCINI, C.; MARCHETTI, A.; FRANCAVIGLIA, R. Estimation of soil organic matter by geostatistical methods: Use of auxiliary information in agricultural and environmental assessment. Ecological Indicators, New York, v. 36, p. 301-314, 2014.

QIAO, J.; ZHU, Y.; JIA, X.; HUANG, L.; SHAO, M. Spatial variation and simulation of the bulk density in a deep profile (0-204 m) on the Loess Plateau, China. Catena, v. 164, p. 88-95, 2018.

R CORE TEAM. R: A language and environment for statistical computing. R Foundation for Statistical Computing, Vienna, Austria, 2016. Disponível em: https://www.r-project.org/. (Acesso em 25/01/2019)

RIBEIRO, L. DA S.; OLIVEIRA, I. R. DE; DANTAS, J. S.; SILVA, C. V. DA; SILVA, G. B. DA; AZEVEDO, J. R. DE. Variabilidade espacial de atributos físicos de solo coeso sob sistemas de manejo convencional e de plantio direto. Pesquisa Agropecuária Brasileira, v. 51, n. 9, p. 1699-1702, 2016.

SABINO, C. V. S.; LAGE, L. V.; ALMEIDA, K. C. DE B. Uso de métodos estatísticos robustos na análise ambiental. Engenharia Sanitária e Ambiental, v. 19, n. spe, 2014.

SAMPAIO, F. de M. T.; FERREIRA, M. M.; OLIVEIRA, M. S. de; ALMEIDA, A. C.; JOSÉ, M. R. Variabilidade espacial da umidade de um Latossolo Vermelho-Amarelo sob plantio direto. Engenharia Agrícola, v. 30, n. 5, p. 854-861, 2010.

SANCHEZ, R. B.; MARQUES JÚNIOR, J.; SOUZA, Z. M. D.; PEREIRA, G. T.; MARTINS FILHO, M. V. Variabilidade espacial de atributos do solo e de fatores de erosão em diferentes pedoformas. Bragantia, v. 68, n. 4, p. 1095-1103, 2009.

SEIDEL, E. J.; OLIVEIRA, M. S. DE. Proposta de uma generalização para os modelos de semivariogramas exponencial e gaussiano. Semina: Ciências Exatas e Tecnológicas, v. 34, n. 1, p. 125-132, 2013.

SILVA, C. L. da; KATO, E. Efeito do selamento superficial na condutividade hidráulica saturada da superfície de um solo sob cerrado. Pesquisa Agropecuária Brasileira, Brasília, v. 32, n. 2, p. 213-220, 1997.

SOUZA, C. K.; MARQUES JÚNIOR, J.; MARTINS FILHO, M. V.; PEREIRA, G. T. Influência do relevo e erosão na variabilidade espacial de um Latossolo em Jaboticabal (SP). Revista Brasileira de Ciência do Solo, v. 27, n. 6, p. 1067-1074, 2003.

SPOHR, R. B.; CARLESSO, R.; GALLÁRRETA, C. G.; PRÉCHAC, F. G.; PETILLO, M. G. Modelagem do escoamento superficial a partir das características físicas de alguns solos do Uruguai. Ciência Rural, Santa Maria, v. 39, n. 1, p. 74-81, 2009.

STOLF, R.; HIROSHI MURAKAMI, J.; BRUGNARO, C.; SILVA, L. G.; FERREIRA DA SILVA, L. C.; CORREIA MARGARIDO, L. A. Penetrômetro de impacto Stolf-programa computacional de dados em EXCEL-VBA. Revista Brasileira de Ciência do Solo, Viçosa, v. 38, n. 3, p. 774782, 2014.

TRANGMAR, B. B.; YOST, R. S.; UEHARA, G. Application of Geostatistics to Spatial Studies of Soil Properties. In: BRADY, N. C. (Ed.).

Advances in Agronomy. Academic Press, v. 38, p. 45-94, 1986. 
VALICHESKI, R. R.; GROSSKLAUS, F.; STÜRMER, S. L. K.; TRAMONTIN, A. L.; BAADE, E. S. A. S. Desenvolvimento de plantas de cobertura e produtividade da soja conforme atributos físicos em solo compactado. Revista Brasileira de Engenharia Agrícola e Ambiental, v. 16, n. 9, p. 969-977, 2012.

VIEIRA, S. R. Geoestatística em estudos de variabilidade espacial do solo. In: NOVAIS, R. F.; ALVAREZ V, V. H.; SCHAEFER, C. E.G.R (Ed.). Tópicos em Ciência do Solo. Viçosa-MG: Sociedade Brasileira de Ciência do Solo, v. 01, p. 1-54, 2000.

WARRICK, A.W.; NIELSEN, D.R. Spatial variability of soil physical properties in the field. In: HILLEL, D. (Ed.). Application of soil physics. New York. Academic Press, 385 p., 1980.

YAMAMOTO,J.K.; LANDIM,P.M.B. Geoestatística: Conceitos e aplicações. Oficina de Texto, 216 p., 2013.

YE, L.; TAN, W.; FANG, L.; Jl, L.; DENG, H. Spatial analysis of soil aggregate stability in a small catchment of the Loess Plateau, China: I. Spatial variability. Soil and Tillage Research, Amsterdam, v. 179, p. 71-81, 2018.

YOUNGS, E.G. Hydraulic conductivity of saturated soils. In: SMITH, K.A. \& MULLINS, C.E., eds. Soil analysis: Physical methods. New York, Marcel Dekker. p.161-207. 1991. 